\title{
II ENCUENTRO SOBRE DIDACTICA DE LA HISTORIA ECONOMICA
}

VICENTE PINILLA

El profesorado universitario dedica una parte sustancial de su tiempo a la docencia. No debería ser, por lo tanto, extraño que de la misma forma que existe una preocupación generalizada por las tareas de investigación y su continuo perfeccionamiento, la búsqueda de una mejora de la calidad de la enseñanza que se quiere transmitir a los alumnos de cualquier ciclo universitario fuera algo consustancial a quien ejerce este trabajo. Sin embargo, es bastante insólito en la Universidad española tener noticia de encuentros o congresos cuyo objetivo sea precisamente reflexionar sobre este tema.

En una primera ocasión, los historiadores de la Economía nos reunimos el año pasado en Zaragoza con el objetivo antes mencionado, y a iniciativa de los profesores de las Areas de Historia e Instituciones Económicas de los Departamentos de Economía Aplicada y Organización de Empresas de la Universidad de Extremadura, y de Estructura e Historia Económicas y Economía Pública de la Universidad de Zaragoza*.

Para centrar el debate de forma adecuada sobre la problemática señala$\mathrm{da}$, los organizadores del primer encuentro, Santiago Zapata y Domingo Gallego, adoptaron una estrategia que a corto y medio plazo está rindiendo excelentes frutos. Se delimitaron inicialmente muy pocos temas, excluyéndose otros de forma consciente, y se comenzó el trabajo por lo que parecían ser elementos claves para una discusión: la función de la historia económica en la formación de los economistas, los objetivos de la asignatura de Historia Económica Mundial y los instrumentos didácticos que pueden ser utilizados en la docencia de Historia Económica.

Se inició, por lo tanto, la tarea por la definición general de la posible utilidad que nuestra disciplina puede tener para la formación de licenciados en Economía, bien sea en su rama general o en la de empresa; se continuó

* Las actas del "I Encuentro sobre Didáctica de la Historia Económica" han sido editadas este mismo año 1991 por el Instituto de Ciencias de la Educación de la Universidad de Zaragoza, en colaboración con el Instituto de Ciencias de la Educación de la Universidad de Extremadura y con el patrocinio de la Diputación General de Aragón. Pueden obtenerse directamente solicitándose al ICE de la Universidad de Zaragoza. 
delimitando los objetivos y planteamiento general de la asignatura más comúnmente representada en los planes de estudio, asignatura básica por su ubicación en el primer curso de carrera, y se cerró el debate a propósito de los medios que se pueden emplear para transmitir con eficacia los objetivos anteriormente enunciados.

El II Encuentro sobre Didáctica de la Historia Económica, realizado en Badajoz los días 30 y 31 de mayo de 1991 , y organizado de nuevo por los Institutos de Ciencias de Educación de las Universidades de Zaragoza y Extremadura, con la colaboración de los Departamentos anteriormente mencionados, pretendía continuar el camino iniciado el año anterior, para lo que retomaba y concretaba algunos de los temas que se habían tratado y lanzaba otros nuevos a la discusión.

Comenzó el encuentro con "Una comparación de los programas de Historia Económica Mundial", realizada por Jaume Torras y Josep Pujol. La vinculación con los debates del año anterior era clara. Si allí se había discutido ya sobre líneas generales y prioridades a la hora de elaborar e impartir el programa de dicha asignatura, ahora se trataba de realizar un examen crítico de los programas que realmente están en vigor, para así continuar el debate anterior.

Torras y Pujol realizaron dos interrogatorios sobre los mencionados programas. En primer lugar sobre su estructura y, posteriormente, sobre los contenidos. Del examen de aquéllos se derivan algunas pautas que son seguidas con mayor generalidad, como la existencia de temas de contenido teórico o metodológico inaugurales; el general eclecticismo a la hora de optar por los criterios de periodización, con predominio de la separación en dos bloques de economías preindustriales e industriales; organización de la exposición en los períodos más antiguos siguiendo criterios de modelización, mientras que para el más reciente se completa aquélla con una pauta espacial y temporal; predominio de las lecciones que se ocupan del período posterior a la Revolución Industrial (generalmente más de dos tercios del programa), constituyendo en este sentido ésta y los procesos de industrialización la parte central de los programas.

En cuanto a contenidos, aparecen como elementos predominantes los modelos o vías nacionales de industrialización. Se sesga en general la materia hacia el estudio del crecimiento económico por grandes regiones en términos muy agregados. Adquieren gran peso los aspectos del crecimiento de la producción, su dinámica comparada y sus interacciones con el entorno institucional, político y social. Por contra, ocupan un espacio muy reducido la distribución de los frutos del crecimiento y las desigualdades dentro de estas unidades y el ahondamiento de lo que es el análisis histórico de una economía moderna (sistema financiero, mercado de trabajo, formas de 
empresa). Tienen, además, menos relevancia de la que parecería lógica temas como el cambio técnico o las formas de organización económica, sus condicionantes y condicionados.

Tras este exhaustivo análisis de contenidos se planteaba en último lugar la enunciación de algunas metas que se deberían alcanzar con un programa de Historia Económica Mundial, y que básicamente serían: una primera formativa, que busque mostrar la pertinencia y la potencialidad del análisis histórico para comprender los grandes procesos económicos (especialmente la materialidad del proceso y su dimensión temporal), y una segunda informativa, que proporcione al futuro economista la cultura histórica imprescindible para enfrentarse a su trabajo.

La ponencia segunda también puede considerarse como prolongación del trabajo previo realizado en Zaragoza, ya que si allí se había plańteado la necesidad de utilizar instrumentos didácticos para la docencia en Historia Económica y, entre otros, se contemplaba la importancia de los materiales estadísticos, aquí se centraba el tema ya sólo en estos últimos, realizándose por parte de Luis María Bilbao y Enrique Llopis una propuesta general de materiales y la explicación de sus posibilidades en las clases.

En este sentido se presentó un material estadístico y gráfico para la historia económica del siglo $\mathrm{XX}$, defendiéndose la necesidad de su utilización en clase por cuanto si el objeto de la Historia Económica es el análisis de las actividades econónicas de las sociedades a lo largo del tiempo, la cuantificación es un elemento imprescindible a la hora de formar a los futuros economistas en estos temas, unido, lógicamente, a la conceptualización. De esta forma, si ambos elementos son claves en la comprensión de la Historia Económica, juntos se refuerzan notablemente. La opción elegida de seleccionar sólo material del siglo XX se justificó con base en algunas de las conclusiones del primer encuentro, referidas a la necesidad de hacer avanzar cronológicamente los programas y de conquistar e integrar la contemporaneidad en nuestras explicaciones, sin hacer dejación de estos temas en otras disciplinas que se imparten en la carrera. Los nuevos planes de estudio, con la inclusión de clases prácticas, son un factor añadido a la hora de reafirmar la importancia de este tipo de materiales.

Los objetivos de estos materiales no deben discrepar de los de la asignatura en general, aun cuando se pueden concretar algunos más específicos como: mostrar y tratar de familiarizar a los estudiantes con las series históricas; intentar fomentar su utilización; contribuir a que dichos estudiantes se inicien en el manejo de algunas técnicas estadísticas de forma práctica, y, por último, contribuir al aprendizaje y medición de los procesos económicos tanto en lo que se refiere a la determinación de tendencias a largo plazo como a la periodización, contrastes espaciales o establecimiento de relaciones concretas y cambiantes entre las variables cconómicas. 
A continuación se expuso el material estadístico y gráfico ofrecido, explicándose los criterios que se habían seguido en su selección, su estructura, lagunas existentes y posibles utilizaciones. Se dedicó, por último, una especial atención a la explotación concreta del mismo.

En la ponencia tercera, "Objetivos y temario del programa de Historia Económica de Españam, se abría una nueva vía de trabajo al iniciarse el debate sobre una asignatura que está presente en un buen número de planes de estudios. Xavier Tafunell presentó un programa para ser impartido en un máximo de sesenta horas reales, lo que condiciona, por la brevedad, su propia configuración. Las limitaciones temporales eran la justificación utilizada para no realizar un temario excesivamente extenso en el que la tensión entre análisis y descripción se vuelque a favor de esta última. Dichas limitaciones le llevan a desechar la idea de explicar la formación y desarrollo del feudalismo en España, comenzándose directamente en el siglo XVI, si bien se realiza primero una introducción.

El programa se organiza para la España moderna en torno a dos hilos argumentales:

1. El Imperio, es decir, la explicación del auge y decadencia de la España imperial (siglos XVI y XVII) y la crisis del Antiguo Régimen en torno al hecho imperial, siendo éste el elemento histórico capaz de anudar planos históricos distintos al de las finanzas del Imperio (sus costes de financiación).

2. El proceso de creciente diferenciación regional que se registra en la segunda mitad de la época moderna, tema que puede entroncarse con el anterior, a través del distinto impacto del Imperio en los diversos reinos y provincias, y también con las características de sus respectivos medios físicos. Esta segunda línea de fuerza permitiría explicar el origen de la diversidad de situaciones en que se encuentran actualmente los diferentes territorios peninsulares y, también, recoger caracteres esenciales de los sistemas económicos y sociales cristalizados a lo largo de varios siglos.

Tras los temas de cierre y apertura de la primera y segunda parte, respectivamente dedicados a la crisis del Antiguo Régimen y a la revolución liberal, se pasa ya de pleno a dicha segunda parte, titulada "El crecimiento económico moderno", que se estructura de forma cronológica, organizándose en grandes etapas. El elemento clave para entender los diversos períodos propuestos sería el de las distintas estrategias de industrialización seguidas, definidas en función de las relaciones mantenidas con la economía internacional. 
De esta forma, tras un tema previo sobre la revolución liberal y otro sobre el crecimiento económico moderno en España, en un análisis cuantitativo a largo plazo, siguen la revolución industrial en el siglo XIX, la vía nacionalista de industrialización, la autarquía, y la liberalización, desarrollo y crisis que van de aquella última a nuestros días.

El número de comunicaciones presentadas fue muy escaso; sólo dos. Una de ellas, extensa y detallada, de Domingo Francisco Verdini, sobre la enseñanza de la historia económica en la Universidad de La Coruña, en la que se explicaban algunos recursos didácticos allí utilizados, y otra de José Luis García Ruiz en la que se hacía una reflexión didáctica sobre historia económica y economía. Además, Alejandro Arizcun expuso los nuevos planes de estudios de las licenciaturas de Economía y Administración de Empresas de la Universidad Pública de Navarra y el lugar que en ellos corresponde a la Historia Económica.

El encuentro se completó, como ya ocurriera en Zaragoza, con dos exposiciones centradas en pedagogía y didáctica. Una, de Carlos Latas, sobre "La evaluación en la Universidad" y otra, de Antonio Rodríguez de las Heras, sobre "Las aplicaciones didácticas del hipertexto".

Hay que señalar que, además de las intervenciones de los ponentes, se suscitó un interesante debate entre los asistentes, y surgió, como en Zaragoza, un buen número de ideas y posibilidades para ser llevadas a la práctica en clase. Se pone de manifiesto, en definitiva, el interés de contrastar nuestras experiencias pedagógicas y de dialogar sobre nuevas ideas que permitan una sensible mejora del producto que ofrecemos a nuestros alumnos.

Debe destacarse, para terminar, el profundo eco que este encuentro ha tenido, dado el alto número de asistentes y la amplísima nómina de universidades representadas, un total de veintitrés. No es, por cllo, de extrañar que el debate sobre la conveniencia de realizar cl III Encuentro en 1992 ó 1993 se resolviera a favor de la primera fecha, dado la amplia nómina de temas que se consideró que todavía quedan por abordar y la conveniencia de aprovechar la especial coyuntura en la que estamos viviendo de discusión y aprobación de nuevos planes de estudio. El probable lugar donde se celebrará dicho encuentro será La Coruña. 